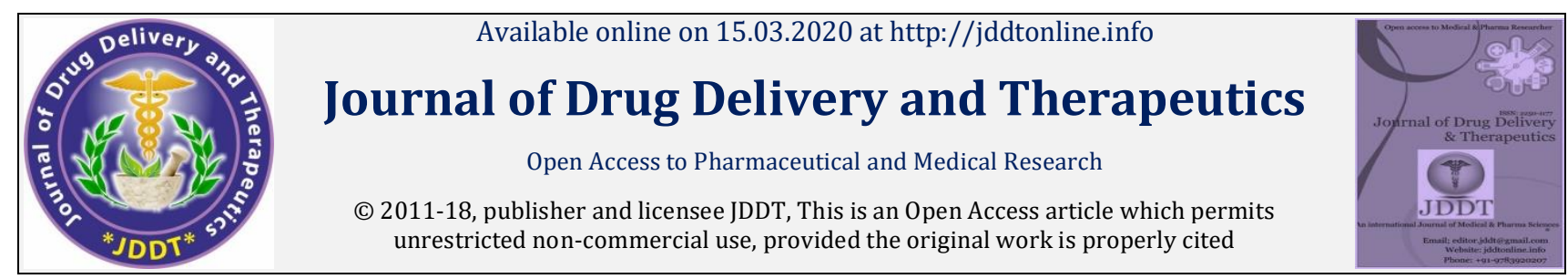

Open Access

Research Article

\title{
Evaluation of the anti-diabetic effect of the methanol leaf extract and fractions of Dennettia tripetala G. Bak (Annonaceae) in alloxan- induced diabetic mice
}

\author{
Abonyi Uchenna $C^{\mathrm{b} *}$, Omoiri Moses $\mathrm{A}^{\mathrm{a}}$, Akah Peter A,b \\ a Department of Pharmacology and Toxicology, Faculty of Pharmaceutical Sciences, Nnamdi Azikiwe University, Awka, Nigeria \\ b Department of Pharmacology and Toxicology, Faculty of Pharmaeutical Sciences, University of Nigeria, Nsukka, Nigeria
}

\begin{abstract}
This study evaluated the anti-diabetic properties of the methanol extract and fractions of Dennettia tripetala leaves in alloxan diabetic rats. The crude methanol extract (ME), n-hexane (NF), ethyl acetate (EAF), butanol (BF) and water (WF) fractions, were tested for anti-diabetic activity in alloxan-induced diabetic mice. The extracts and its fractions were screened for phytochemical constituents. Glibenclamide was used as the standard anti-diabetic treatment Fasting blood glucose (FBG) levels were determined using a glucometer. Lipid profile parameters were also assessed. Histopathological examination of the pancreas was performed. The presence of glycosides, saponins, reducing sugars, fats and oil, alkaloids, carbohydrates, flavonoids, proteins and tannins were detected in ME, and the fractions. Treatment of the rats with the extract and its fractions reduced FBG levels significantly $(\mathrm{p}<0.05)$ within 10 hours of acute treatment and 14 days short term treatment. The highest reduction was by the crude extract, ( ME $500 \mathrm{mg} / \mathrm{kg}$ ) with percentage reduction of $62.89 \%$. The study revealed significant (p < 0.05 ) reductions in serum triglyceride, serum cholesterol and LDL levels by the extracts and its fractions while a significant (p < 0.05 ) increase in HDL levels was evident. The effect of the extract and fractions on body weight indicated a moderate weight gain. Treatment with high dose of the extract and fractions $(500 \mathrm{mg} / \mathrm{kg}$ ) resulted in marked rejuvenation of the pancreatic $\beta$ cells. The results of this study suggest that the leaves of Dennetia tripetala are endowed with potent anti-diabetic and antilipidemic properties.
\end{abstract}

Keywords: Dennetia tripetala, Antidiabetic, Alloxan, Lipid profile, Histopathplogy.

Article Info: Received 06 Jan 2020; Review Completed 17 Feb 2020; Accepted 28 Feb 2020; Available online 15 March 2020

\section{口if:}

Abonyi UC, Omoiri MA, Akah PA, Evaluation of the anti-diabetic effect of the methanol leaf extract and fractions of Dennettia tripetala G. Bak (Annonaceae) in alloxan- induced diabetic mice, Journal of Drug Delivery and Therapeutics. 2020; 10(2):129-139 http://dx.doi.org/10.22270/jddt.v10i2.3969

*Address for Correspondence:

Abonyi Uchenna C, Department of Pharmacology and Toxicology, Faculty of Pharmaeutical Sciences, University of Nigeria, Nsukka, Nigeria

\section{INTRODUCTION}

Diabetes mellitus (DM) is a common disorder of the endocrine system which leads to impairment of glucose homeostasis resulting in severe complications such as retinopathy, angiopathy, nephropathy, neuropathy and neurological disorders [1]. It is a serious global health challenge characterized by hyperglycemia resulting from absolute or relative deficiency of insulin or by insulin resistance at the cellular level [2]. Features of DM may include lipoprotein abnormalities [3], elevated basal metabolic rate [4], reactive oxygen species scavenging enzymes deficiency [5] and damage to pancreatic beta cells induced by high oxidative stress [6]. Trivedi [7] reported that diabetes mellitus ranks seventh among the leading causes of death and is considered third when it's lethal and debilitating complications are taken into consideration. Despite the tremendous achievements by pharmaceutical companies to produce different types of oral hypoglycaemic agents alongside insulin for the treatment of diabetes, there is still an increase in the demand of natural products with antidiabetic activities [8]. The use of medicinal plants as agents to control diabetes mellitus have been reported [9] Metformin, a very effective hypoglycemic drug was discovered by the traditional approach, through the use of Galega officinialis [10]. The continuous efforts by man to exploit medicinal plants for the treatment of several diseases including diabetes is essentially because the side effects associated with herbal medicine are few compared to that associated with chemically synthesized drugs. Dennettia tripetala (pepper fruit) is of Annonaceae family. It is a tropical plant that is mostly dominant in West African region especially Cameroon, Ivory Coast and Nigeria [11, 12]. The plant is characterized by its pungent like spicy and pepperish taste, which makes it suitable for spices and condiments [13]. Its mature fruit is masticated as a fresh green, freshly 
ripened red, black dry fruit and dry de-hulled seed [14]. In Nigeria, it is locally called "Nkarika" ( Calabar), "Ako" (Edo), "Opipi" (Idoma), "Mmimi" (Igbo) and "Ata igbere" (Yoruba). The medicinal properties of the plant has been associated to the presence of saponins, flavonoids, tannins, alkaloids, terpenoids, and cyanogenic glycosides $[15,16]$. Its activities against microbial related and coronary diseases are linked to the presence of these phytochemicals [17]. The leaves and roots have been used locally to treat various ailment including fever, infantile convulsion, typhoid, worm infestation, vomiting and stomach upset [18]. The leaf extract has been demonstrated to possess antimicrobial activity against Staphylococcus aureus. [18], antinociceptive, antiinflammatory, antioxidant and antimicrobial activities [19]. In the present study, the antidiabetic properties of Dennettia tripetala was assessed by evaluating the antihyperglycemic and hypolipidemic activities of the extract and fractions in alloxan- induced diabetic mice.

\section{MATERIALS AND METHODS}

\subsection{Drugs and Chemicals}

The chemicals and drugs were used for this study include, alloxan monohydrate (Sigma LTD USA), glibendamide (NGC, Nigeria), methanol, n-hexane, ethyl acetate, butanol, chloroform, (JHD, Guangdong Guanghua Schi-Tech. Ltd China), formaldehyde $40 \% \mathrm{w} / \mathrm{v}$ (May and Baker Ltd, Dagenham England), Tween-80 (Sigma Aldrich, Germany) DPPH,(Sigma Aldrich, Germany), ascorbic acid (Sigma Aldrich, Germany). total cholesterol, triglyceride, high density lipoprotein cholesterol kits (Randox Laboratories Limited, Country Atrium, United kingdom).

\subsection{Plant Materials}

Fresh leaves of Denettia tripetala were collected from Irri Town, Isoko South Local Government Area, Delta State, Nigeria. The plant was authenticated by Mr. Patrick Ugwuozo of the Department of Botany, Nnamdi Azikiwe University, Awka, with voucher number PCG/UNIZIK/0631. The fresh leaves were washed in a running tap to remove dust and other debris, and air dried for two weeks. The dried leaves were pulverized with electrical blender and kept in clean air tight amber bottle. About, $750 \mathrm{~g}$ of the powdered material was cold macerated in $80 \%$ ethanol. The mixture was agitated continually for two days (48 hours), and then filtered using Whatman filter paper No 1 . The filtrate was concentrated to dryness using water bath at $40^{\circ} \mathrm{C}$. The extract was stored in a refrigerator before use. The percentage yield of the extract was calculated.

\subsection{Fractionation of Crude Extract}

Fractionation was carried out using n-hexane, ethyl acetate and butanol following the method described by Ihekwereme et al [19]. Methanol crude extract (100 g) was dispersed in $500 \mathrm{ml}$ of distill water and then poured into a separating funnel. $\mathrm{N}$-hexane $500 \mathrm{ml}$ was then added to the funnel and was shaken thoroughly to mix. The mixture was allowed to separate into two distinct layers. The n-hexane portion, (upper layer) was separated and the other portion was subjected to fresh n-hexane until the n-hexane solvent became clear. After the n-hexane phase, the other portion was subjected to ethyl acetate and butanol successively. The various fractions were concentrated to dryness using water bath at $40^{\circ} \mathrm{C}$.

\subsection{Experimental Animals}

A total of 100 male albino mice, (18-35 g) were purchased from the Laboratory Animal Facility of the Department of Veterinary Physiology and Pharmacology, University of Nigeria, Nsukka and transferred to the animal House of the Department of Pharmacology and Toxicology, Nnamdi Azikiwe University. They were housed in clean metal cages, with free access to water and feed (Guniea Feed $\AA$, Nigeria). Animals were handled in compliance with the National Institute of Health Guidelines for care and use of laboratory animals (Pub No. 85-23, revised 1985).

\subsection{Experimental Design}

A total of 65 mice consisting of 60 diabetic mice randomized into 12 groups of 5 mice each and 5 non-diabetic mice and were treated as follows: Group 1 (Normal control) received $5 \%$ Tween $80(5 \mathrm{ml})$, Group 2 (Diabetic control) received 5 $\%$ Tween $80(5 \mathrm{ml})$, Group 3 received glibenclamide (5 $\mathrm{mg} / \mathrm{kg}$ ), Groups 4 and 5 received 250 and $500 \mathrm{mg} / \mathrm{kg}$ of methanol crude extract respectively, Groups 6 and 7 received 250 and $500 \mathrm{mg} / \mathrm{kg}$ of ethyl acetate fraction respectively, Groups 8 and 9 received 250 and $500 \mathrm{mg} / \mathrm{kg}$ of $\mathrm{n}$-hexane fraction respectively, Groups 10 and 11 received butanol fraction 250 and $500 \mathrm{mg} / \mathrm{kg}$ respectively while Groups 12 and 13 received aqueous fraction 250 and $500 \mathrm{mg} / \mathrm{kg}$ respectively.

\subsection{Blood Glucose determination}

Baseline pretreatment blood glucose level (zero hour) of the mice was taken. Then diabetic animals were then treated as stated. Blood glucose level was measured at 2, 4, 6, 8 and 10 hours post treatment using One Touch Ultramini Glucometer (LifeScan GmbH Switserland) [20]. Daily administration of glibenclamide, crude extract and fractions was also carried out for a period of 14 days ( 2 weeks) on the same animals. Blood glucose level was measured on day 2, 4, 6, 8, 10, 12 and 14. Blood samples were obtained from the tail vein of the mice.

\subsection{Determination of serum total cholesterol}

Serum total cholesterol (TC) was evaluated using Randox commercial assay kits following the methods described by Ezeigbo [21]. One millilitre (1 $\mathrm{ml})$ of the working cholesterol reagent was added into tubes labeled blank, standard and test groups. Ten microlitres of standard cholesterol reagent, and samples were added into their respective tubes. They were mixed and allowed to stand for 10 minutes at room temperature. Absorbance of samples and standard were read with the aid of a spectrophotometer at $500 \mathrm{~nm}$. Total cholesterol level in sample was calculated using the formula below;

$$
\text { Total Cholesterol }(\mathrm{mg} / \mathrm{dl})=\frac{\text { Absorbance of sample }}{\text { Absorbance of standard }} \times \text { Concentrationof standard }
$$




\subsection{Determination of serum triglyceride}

Serum triglyceride was evaluated using Randox commercial assay kits following the methods described by Tietz [22] One millilitre $(1 \mathrm{ml})$ of the working triglyceride reagent was added into tubes labeled blank, standard and test groups. Ten microlitres of standard triglyceride reagent, and samples were added into their respective tubes. They were mixed and allowed to stand for 10 minutes at room temperature. Absorbance of samples and standard were read with the aid of a spectrophotometer at $500 \mathrm{~nm}$. Total cholesterol level in sample was calculated using the formula below;

$$
\text { Total triglycride }(\mathrm{mg} / \mathrm{dl})=\frac{\text { Absorbance of sample }}{\text { Absorbance of } \text { standard }} \times \text { Concentartion of standard }
$$

\subsection{Determination of serum high density Lipoprotein cholesterol (HDL-cholesterol)}

Serum HDL-cholesterol was evaluated using Randox commercial assay kits following the methods developed by National Institute of Health Consensus Development Conference Statement [23]. One hundred microlitres (100 ul) of samples and standard cholesterol reagent were dispensed into test tubes containing $250 \mathrm{ul}$ of HDL cholesterol precipitate (R1). The mixture was centrifuged at $4000 \mathrm{rpm}$ for 10 minutes. Thereafter, $100 \mathrm{uL}$ of samples and standard supernatants were added to another set of test tubes labeled samples and standard containing cholesterol reagent. The mixture was incubated for 10 minutes at room temperature and absorbance of standard and samples were measured against reagent blank at $500 \mathrm{~nm}$ within 60 minutes using Spectrophotometer. HDL-cholesterol level in sample was calculated using the formula below;

$$
H D L \text { Cholesterol }(\mathrm{mg} / \mathrm{dl})=\frac{\text { Absorbance of sample }}{\text { Absorbance of standard }} \times \text { Concentration of standard }
$$

\subsection{Determination of serum low density Lipoprotein cholesterol (LDL-cholesterol)}

Low density lipoproteins (LDL) cholesterol in serum was calculated using the equation described by Friedewald et al.
[24]. The Friedewald's equation estimates the value of HDL$\mathrm{C}$ using the values of total cholesterol, triglyceride and HDLcholesterol.

$$
L D L \text { cholesterol }(\mathrm{mg} / \mathrm{dl})=\text { Total cholesterol }-\frac{\text { Triglycerides }}{5}-H D L \text { Cholesterol }
$$

\subsection{Histopathological studies}

The pancreases harvested from the animals were preserved using 10\% neutral buffered formalin placed in pre labeled universal containers. The pancreases were dissected and placed in labeled tissue cassettes and the thickness maintained between $3-5 \mathrm{~mm}$ [25]. The pancreases were subjected to automatic tissue processing using the Leica TP2010 automatic tissue processor for 18 hours passing them through the four stages of tissue processing namely: fixation (using 10\% neutral buffered formalin), dehydration (using ascending grades of isopropyl alcohol), clearing or dealcoholisation (using xylene) and finally impregnation or infiltration (using molten paraffin wax) [26]. The tissues were then embedded in paraffin wax using the Leica automated tissue embedder and sectioned to get ultra thin sections at five (5) microns, using the thermo scientific semi automated rotary microtome. The tissues were floated out from the thermo scientific digital floating bath on frosted end pre labeled slides and dried on the thermo scientific digital slimline hot plate. The tissues were further dried in the hot air oven overnight and subjected to hematoxylin and eosin staining to demonstrate the general tissue structure. Stained slides were mounted in DPX and allowed to dry before viewing under the microscope using X10 and X 40 magnification.

\subsection{Statistical Analysis}

The data obtained were expressed as mean \pm SD and were analysed using Statistical Product and Service Solutions (SPSS), version 20. Tests of statistical significance were carried out using one way Analysis of Variance (ANOVA) followed by post hoc turkeys test. $\mathrm{P}$ values $<0.05$ were considered statistically significant.

\section{RESULTS}

\subsection{Percentage yields of extract and fractions}

The yield of methanol crude extract was $200 \mathrm{~g}$ (26.67\%) while the percent yield of the fractions $(\mathrm{w} / \mathrm{w})$ were: $\mathrm{n}$ hexane (25\%), ethyl acetate (30\%), butanol (21\%) and water (19\%).

\subsection{Phytochemical analysis.}

The extract and fractions contained saponins, carbohydrates, resins, alkaloids, flavonoids, tannins, cardiac glycosides and reducing sugars. Flavonoids, saponins, alkaloids, and tannins were present in large amount in the crude extract. The ethyl acetate fraction contained saponins, flavonoids and tannins in large amount while steroids, alkaloids and cardiac glycosides were in moderate amount. The $\mathrm{n}$ hexane fraction had saponins, flavonoids and alkaloids in large quantity but is devoid of other phytoconstituents. The butanol fraction had terpenoids, steroids and tannins in large amounts but is devoid of other constituents. Water fraction contained more of saponins Table 1).

\subsection{Effect of crude extract and fractions on fasting blood} glucose (FBG) level .

The crude methanol extract and fractions reduced fasting blood glucose levels in alloxan- induced diabetic mice from 2 $-10 \mathrm{hr}(\mathrm{p}<0.05)$. The highest reduction $(62.58 \%)$ in FBS was by the $B F(250 \mathrm{mg} / \mathrm{kg})$, at the $6^{\text {th }}$ hour. By the $10^{\text {th }}$ hour, a percentage reduction of 61.76 and $61.09 \%$ was evoked by ME, 250 and $500 \mathrm{mg} / \mathrm{kg}$ respectively (Table 2). 
Table 1: Results of phytochemical analysis of methanol crude extract and fractions of Dennettia tripetala leaves

\begin{tabular}{|c|c|c|c|c|c|c|}
\hline & & Crude extract & $\begin{array}{l}\text { n-haxane } \\
\text { fraction }\end{array}$ & $\begin{array}{l}\text { Ethyl acetate } \\
\text { fraction }\end{array}$ & $\begin{array}{l}\text { Butanol } \\
\text { fraction }\end{array}$ & $\begin{array}{l}\text { Water } \\
\text { fraction }\end{array}$ \\
\hline 1 & Saponins & +++ & +++ & +++ & + & ++ \\
\hline 2 & Tannins & +++ & ++ & +++ & ++ & + \\
\hline 3 & Carbohydrates & ++ & + & ++ & + & + \\
\hline 4 & Reducing Sugars & + & + & + & + & + \\
\hline 5 & Flavonoids & +++ & +++ & +++ & + & + \\
\hline 7 & Alkaloids & ++ & ++ & + & + & - \\
\hline 8 & Glycosides & ++ & ++ & ++ & - & + \\
\hline 9 & Steroids & + & + & + & + & + \\
\hline 10 & Fats and oils & ++ & + & + & + & - \\
\hline 11 & Proteins & ++ & + & - & - & - \\
\hline 12 & Acidic compounds & - & - & - & - & - \\
\hline
\end{tabular}

$(-)=>$ Not Present, $(+)=>$ Present in small concentration, $(++)=>$ Present in moderately high concentration, $(+++)=>$ Present in high concentration.

Table 2: Effect of various treatments on blood glucose level (hourly study)

\begin{tabular}{|c|c|c|c|c|c|c|c|}
\hline & \multirow{2}{*}{$\begin{array}{l}\text { Dose } \\
(\mathrm{mg} / \mathrm{kg})\end{array}$} & \multicolumn{6}{|l|}{ FBS (mg/dl) } \\
\hline & & $0 \mathrm{hr}$ & $2 \mathrm{hr}$ & $4 \mathrm{hr}$ & $6 \mathrm{hr}$ & $8 \mathrm{hr}$ & $10 \mathrm{hr}$ \\
\hline \multirow{2}{*}{$\begin{array}{l}\text { Normal } \\
\text { control }\end{array}$} & Tween 80 & $100.40 \pm 3.57$ & $97.00 \pm 6.50$ & $99.00 \pm 6.22$ & $89.80 \pm 6.49$ & $88.00 \pm 5.39$ & $96.80 \pm 10.24$ \\
\hline & $5 \mathrm{ml}$ & & $(3.4 \%)$ & $(1.4 \%)$ & $(10.6 \%)$ & $(12.4 \%)$ & $(3.6 \%)$ \\
\hline \multirow{2}{*}{$\begin{array}{l}\text { Diabetic } \\
\text { control }\end{array}$} & Tween 80 & $447.40 \pm 30.94$ & $457.60 \pm 27.60$ & $459.80 \pm 26.755$ & $462.60 \pm 26.96$ & $430.20 \pm 42.26$ & $463.60 \pm 26.98$ \\
\hline & $5 \mathrm{ml}$ & & $(-2.28 \%)$ & $(-2.77 \%)$ & $(-3.39 \%)$ & $(-3.89 \%)$ & $(-3.62 \%)$ \\
\hline \multirow[t]{2}{*}{ Glibenclamide } & 5 & $409.50 \pm$ & $333.90 \pm 32.28$ & $189.00 \pm 28.72^{*}$ & $190.80 \pm 27.20^{*}$ & $196.80 \pm 26.23^{*}$ & $187 \pm 25.09 *$ \\
\hline & & 26.91 & $(18.46 \%)$ & $(53.85 \%)$ & $(53.41 \%)$ & $(51.94 \%)$ & (54.33\%) \\
\hline \multirow{4}{*}{$\begin{array}{l}\text { Methanol } \\
\text { Extract }\end{array}$} & 250 & $497.20 \pm 53.75$ & $354.70 \pm 52.84$ & $195.80 \pm 50.55^{*}$ & $193.50 \pm 48.40^{*}$ & $190.09 \pm 44.99 *$ & $190.00 \pm 43.50 *$ \\
\hline & & & $(28.66 \%)$ & $(60.6 \%)$ & $(61.08 \%)$ & $(61.76 \%)$ & $(61.76 \%)$ \\
\hline & 500 & $503.80 \pm 14.63$ & $300.60 \pm 23.85^{*}$ & $270.90 \pm 23.82^{*}$ & $270.73 \pm 28.19 *$ & $199.00 \pm 29.11^{*}$ & $196.10 \pm 34.46^{*}$ \\
\hline & & & $(40.33 \%)$ & $(46.23 \%)$ & $(46.26 \%)$ & $(60.50 \%)$ & $(61.09 \%)$ \\
\hline \multirow{4}{*}{$\begin{array}{l}\text { Ethyl acetate } \\
\text { fraction }\end{array}$} & 250 & $386.00 \pm 27.98$ & $340.90 \pm 2742$ & $197.74 \pm 19.50^{*}$ & $180.90 \pm 18.98^{*}$ & $290.00 \pm 18.25^{*}$ & $290.00 \pm 17.97^{*}$ \\
\hline & & & $(11.68 \%)$ & $(48.77 \%)$ & $(53.37 \%)$ & $(24.87 \%)$ & $(24.87 \%)$ \\
\hline & 500 & & $400.20 \pm 86.50$ & $180.00 \pm 55.96^{*}$ & $190.61 \pm 17.00^{*}$ & $211.40 \pm 20.70^{*}$ & $250.00 \pm 25.62 *$ \\
\hline & & $503.80 \pm 96.12$ & $(20.56 \%)$ & $(64.27 \%)$ & $(62.17 \%)$ & $(58.03 \%)$ & $(50.38 \%)$ \\
\hline \multirow{4}{*}{$\begin{array}{l}\text { n-hexane } \\
\text { fraction }\end{array}$} & 250 & $460.60 \pm 16.92$ & $452.00 \pm 17.50$ & $196.70 \pm 17.01^{*}$ & $180.00 \pm 17.07^{*}$ & $342.00 \pm 18.06$ & $280.00 \pm 14.51^{*}$ \\
\hline & & & $(1.87 \%)$ & $(57.29 \%)$ & $(60.92 \%)$ & $(25.75 \%)$ & $(44.41 \%)$ \\
\hline & 500 & $450.00 \pm 10.08$ & $362.00 \pm 8.97$ & $194.00 \pm 8.60^{*}$ & $199.00 \pm 9.56^{*}$ & $200.90 \pm 7.10^{*}$ & $300.00 \pm 6.41^{*}$ \\
\hline & & & $(19.55 \%)$ & $(56.89 \%)$ & $(55.77 \%)$ & $(55.35 \%)^{*}$ & $(33.33 \%)$ \\
\hline \multirow{5}{*}{$\begin{array}{l}\text { Butanol } \\
\text { fraction }\end{array}$} & 250 & $481.40 \pm 15.95$ & $320.00 \pm 15.73^{*}$ & $190.00 \pm 15.44^{*}$ & $180.00 \pm 15.38^{*}$ & $240.00 \pm 16.62^{*}$ & $290.00 \pm 15.15^{*}$ \\
\hline & & & $(33.47 \%)$ & $(60.53 \%)$ & $(62.58 \%)$ & $(50.10 \%)$ & $(39.79 \%)$ \\
\hline & 500 & $480.40 \pm 4.06$ & $300.00 \pm 12.11^{*}$ & $191.50 \pm 13.31^{*}$ & $180.52 \pm 11.63^{*}$ & $217.70 \pm 8.70^{*}$ & $300.00 \pm 10.67^{*}$ \\
\hline & & & $(37.58 \%)$ & $(60.18 \%)$ & $(62.34 \%)$ & $(54.68 \%)$ & $(37.55 \%)$ \\
\hline & & $489.80 \pm 34.54$ & $312.00 \pm 20.53^{*}$ & $200.00 \pm 19.96^{*}$ & $211.00 \pm 18.77^{*}$ & $230.00 \pm 18.30^{*}$ & $250.00 \pm 18.66^{*}$ \\
\hline \multirow[t]{3}{*}{ Water fraction } & 250 & & $(36.30 \%)$ & $(59.17 \%)$ & $(56.92 \%)$ & $(53.04 \%)$ & $(48.96 \%)$ \\
\hline & 500 & $428.60 \pm 13.17$ & $333.00 \pm 34.67^{*}$ & $189.90 \pm 36.58^{*}$ & $200.70 \pm 34.68^{*}$ & $230.60 \pm 29.23^{*}$ & $255.00 \pm 30.10^{*}$ \\
\hline & & & (22.19\%) & $(55.69 \%)$ & $(53.25 \%)$ & $(46.34 \%)$ & $(40.50 \%)$ \\
\hline
\end{tabular}

$\left.\mathrm{n}=5{ }^{*} \mathrm{p}<0.05\right)$ when compared to diabetic control 


\subsection{Effect of two weeks treatment on blood glucose level}

Daily treatment with the crude methanol extract and fractions for 14 days reduced fasting blood glucose levels from the $2^{\text {nd }}$ to the $14^{\text {th }}$ day with the exception of ME (500 $\mathrm{mg} / \mathrm{kg}$ ). Significant $(\mathrm{p}<0.05)$ reduction in FBG levels was evident at $500 \mathrm{mg} / \mathrm{kg}$ of the extract and fractions. The highest reduction in FBG levels was by ME $(500 \mathrm{mg} / \mathrm{kg} 62.89$ $\%$ ), followed by BF (250 mg/kg 59.40\%) at day 14 (Table 3).

Table 3: Effect of various treatments in blood glucose level (Daily study)

\begin{tabular}{|c|c|c|c|c|c|c|c|c|c|}
\hline \multicolumn{10}{|c|}{ Fasting blood glucose (mg/dl) } \\
\hline Treatment & $\begin{array}{l}\text { Dose } \\
(\mathrm{mg} / \mathrm{k} \\
\mathrm{g})\end{array}$ & Day 0 & Day 2 & Day 4 & Day 6 & Day 8 & Day 10 & Day 12 & Day14 \\
\hline $\begin{array}{l}\text { Normal } \\
\text { control }\end{array}$ & $\begin{array}{l}\text { Tween } \\
80 \\
5 \mathrm{ml}\end{array}$ & $\begin{array}{l}93.20 \pm 2.2 \\
7\end{array}$ & $\begin{array}{l}89.40 \pm 10.0 \\
9 \\
(4.08 \%)\end{array}$ & $\begin{array}{l}79.60 \pm 14.7 \\
7 \\
(14.6 \%)\end{array}$ & $\begin{array}{l}87.20 \pm 16.8 \\
9 \\
(6.4 \%)\end{array}$ & $\begin{array}{l}92.20 \pm \\
12.55 \\
(1.07 \%)\end{array}$ & $\begin{array}{l}78.60 \pm 9.37 \\
(14.6 \%)\end{array}$ & $\begin{array}{l}84.60 \pm 2.27 \\
(15.7 \%)\end{array}$ & $\begin{array}{l}89.80 \pm 18.1 \\
4 \\
(3.6 \%)\end{array}$ \\
\hline $\begin{array}{l}\text { Diabetic } \\
\text { control }\end{array}$ & $"$ & $\begin{array}{l}395.87 \pm 31 \\
.17\end{array}$ & $\begin{array}{l}397.54 \pm 58 \\
61 \\
(-0.42 \%)\end{array}$ & $\begin{array}{l}398.00 \pm 25 \\
94 \\
(-0.54 \%)\end{array}$ & $\begin{array}{l}399.00 \pm 26 . \\
30 \\
(-0.79 \%)\end{array}$ & $\begin{array}{l}400.67 \pm 26 \\
13 \\
(-1.21 \%)\end{array}$ & $\begin{array}{l}454.97 \pm 26 \\
01 \\
(-14.93 \%)\end{array}$ & $\begin{array}{l}490.89 \pm 24 \\
13 \\
(-24.00 \%)\end{array}$ & $\begin{array}{l}600.18 \pm 32 \\
66 \\
(-51.61 \%)\end{array}$ \\
\hline $\begin{array}{l}\text { Glibenclam } \\
\text { ide }\end{array}$ & 5 & $\begin{array}{l}400.00 \pm 29 \\
.23\end{array}$ & $\begin{array}{l}301.00 \pm 48 . \\
14^{*} \\
(24.75 \%)\end{array}$ & $\begin{array}{l}300.00 \pm 21 \\
58^{*} \\
(25.00 \%)\end{array}$ & $\begin{array}{l}290.00 \pm 20 . \\
42^{*} \\
(27.5 \%)\end{array}$ & $\begin{array}{l}250.00 \pm 19 . \\
01^{*} \\
(37.5 \%)\end{array}$ & $\begin{array}{l}219.01 \pm 16 \\
14^{*} \\
(37.5 \%)\end{array}$ & $\begin{array}{l}190.80 \pm 20 \\
23 * \\
(52.3 \%)\end{array}$ & $\begin{array}{l}180.40 \pm 16 \\
90 * \\
(55.00 \%)\end{array}$ \\
\hline \multirow[t]{2}{*}{$\begin{array}{l}\text { Methanol } \\
\text { Extract }\end{array}$} & 250 & $\begin{array}{l}378.00 \pm 40 \\
.55\end{array}$ & $\begin{array}{l}311.70 \pm 95 \\
77^{*} \\
(17.5 \%)\end{array}$ & $\begin{array}{l}295.40 \pm 39 . \\
60 * \\
(21.85 \%)\end{array}$ & $\begin{array}{l}213.86 \pm 37 . \\
25^{*} \\
(43.42 \%)\end{array}$ & $\begin{array}{l}193.69 \pm 39 . \\
10^{*} \\
(49.02 \%)\end{array}$ & $\begin{array}{l}193.86 \pm 37 . \\
12^{*} \\
(48.71 \%)\end{array}$ & $\begin{array}{l}191.56 \pm 30 . \\
81 * \\
(49.32 \%)\end{array}$ & $\begin{array}{l}174.90 \pm 31 . \\
93^{*} \\
(53.99 \%)\end{array}$ \\
\hline & 500 & $\begin{array}{l}415.00 \pm 24 \\
.49\end{array}$ & $\begin{array}{l}398.40 \pm 75 \\
24 \\
(4 \%)\end{array}$ & $\begin{array}{l}365.80 \pm 34 \\
13 \\
(11.85 \%)\end{array}$ & $\begin{array}{l}300.87 \pm 34 \\
42^{*} \\
(27.50 \%)\end{array}$ & $\begin{array}{l}209.09 \pm 37 \\
47 * \\
(49.63 \%\end{array}$ & $\begin{array}{l}160.00 \pm 35 \\
23 * \\
(61.45 \%)\end{array}$ & $\begin{array}{l}160 \pm 36.09 * \\
(61.45 \%)\end{array}$ & $\begin{array}{c}154 \pm 40.21 * \\
(62.89 \%)\end{array}$ \\
\hline \multirow[t]{2}{*}{$\begin{array}{l}\text { Ethyl } \\
\text { acetate } \\
\text { fraction }\end{array}$} & 250 & $\begin{array}{l}387.20 \pm 27 \\
.93\end{array}$ & $\begin{array}{l}357.00 \pm 37 \\
42^{*} \\
(7.79 \%)\end{array}$ & $\begin{array}{l}330.98 \pm 16 \\
86^{*} \\
(14.52 \%)\end{array}$ & $\begin{array}{l}300.00 \pm 15 \\
42 * \\
(22.48 \%)\end{array}$ & $\begin{array}{l}254.78 \pm 14 . \\
90 * \\
(34.19 \%)\end{array}$ & $\begin{array}{l}200.00 \pm 14 . \\
66 * \\
(48.35 \%)\end{array}$ & $\begin{array}{l}198.76 \pm 13 . \\
25 * \\
(48.66 \%)\end{array}$ & $\begin{array}{l}172.00 \pm 17 . \\
5^{*} \\
(55.59 \%)\end{array}$ \\
\hline & 500 & $\begin{array}{l}319.09 \pm 94 \\
.87\end{array}$ & $\begin{array}{l}314.98 \pm 8.4 \\
3 \\
(1.28 \%)\end{array}$ & $\begin{array}{l}309.00 \pm 3.6 \\
8 \\
(3.16 \%)\end{array}$ & $\begin{array}{l}210.00 \pm 5.2 \\
5^{*} \\
(34.89 \%)\end{array}$ & $\begin{array}{l}200.00 \pm 6.5 \\
8^{*} \\
(40.77 \%)\end{array}$ & $\begin{array}{l}189.00 \pm 8.2 \\
1^{*} \\
(40.76 \%)\end{array}$ & $\begin{array}{l}180.00 \pm 9.0 \\
4^{*} \\
(43.59 \%)\end{array}$ & $\begin{array}{l}150.00 \pm 9.5 \\
0^{*} \\
(52.99 \%)\end{array}$ \\
\hline \multirow[t]{2}{*}{$\begin{array}{l}\text { n-hexane } \\
\text { fraction }\end{array}$} & 250 & $\begin{array}{l}380.00 \pm 11 \\
.03\end{array}$ & $\begin{array}{l}343.00 \pm 32 \\
84 * \\
(9.7 \%)\end{array}$ & $\begin{array}{l}317.00 \pm 14 \\
61^{*} \\
(16.58 \%)\end{array}$ & $\begin{array}{l}301.08 \pm 14 \\
33^{*} \\
(20.77 \%)\end{array}$ & $\begin{array}{l}217.80 \pm 19 . \\
74 * \\
(42.89 \%)\end{array}$ & $\begin{array}{l}195.00 \pm 20 . \\
89 * \\
(48.68 \%)\end{array}$ & $\begin{array}{l}190.09 \pm 23 \\
78^{*} \\
(50.00 \%)\end{array}$ & $\begin{array}{l}160.00 \pm 25 \\
81^{*} \\
(57.89 \%)\end{array}$ \\
\hline & 500 & $\begin{array}{l}365.20 \pm 9 . \\
28\end{array}$ & $\begin{array}{l}333.90 \pm 29 . \\
65^{*} \\
(8.57 \%)\end{array}$ & $\begin{array}{l}304.44 \pm 15 . \\
14^{*} \\
(16.64 \%)\end{array}$ & $\begin{array}{l}200.80 \pm 15 . \\
96 * \\
(45.02 \%)\end{array}$ & $\begin{array}{l}199.90 \pm 16 . \\
33 * \\
(45.26 \%)\end{array}$ & $\begin{array}{l}182.90 \pm 14 . \\
79 * \\
(49.91 \%)\end{array}$ & $\begin{array}{l}177.00 \pm 5.1 \\
2^{*} \\
(51.53 \%)\end{array}$ & $\begin{array}{l}152.00 \pm 5.5 \\
0^{*} \\
(58.38 \%)\end{array}$ \\
\hline \multirow[t]{2}{*}{$\begin{array}{l}\text { Butanol } \\
\text { fraction }\end{array}$} & 250 & $\begin{array}{l}372.00 \pm 11 \\
.42\end{array}$ & $\begin{array}{l}342.70 \pm 33 . \\
86^{*} \\
(7.88 \%)\end{array}$ & $\begin{array}{l}318.89 \pm 15 . \\
95^{*} \\
(12.39 \%)\end{array}$ & $\begin{array}{l}301.00 \pm 18 \\
36^{*} \\
(19.08 \%)\end{array}$ & $\begin{array}{l}299.70 \pm 20 \\
41^{*} \\
(19.44 \%)\end{array}$ & $\begin{array}{l}290.89 \pm 21 \\
60 * \\
(21.80 \%)\end{array}$ & $\begin{array}{l}199.00 \pm 21 . \\
78^{*} \\
(46.50 \%)\end{array}$ & $\begin{array}{l}151.00 \pm 22 . \\
46^{*} \\
(59.40 \%)\end{array}$ \\
\hline & 500 & $\begin{array}{l}364.00 \pm 11 \\
.71\end{array}$ & $\begin{array}{l}355.00 \pm 10 . \\
97 \\
(2.47 \%)\end{array}$ & $\begin{array}{l}322.14 \pm 9.4 \\
2^{*} \\
(11.54 \%)\end{array}$ & $\begin{array}{l}211.64 \pm 11 \\
12^{*} \\
(41.86 \%)\end{array}$ & $\begin{array}{l}203.90 \pm 7.6 \\
2^{*} \\
(43.98 \%)\end{array}$ & $\begin{array}{l}184.00 \pm 8.3 \\
5^{*} \\
(49.45 \%)\end{array}$ & $\begin{array}{l}175.00 \pm 7.9 \\
2^{*} \\
(51.92 \%)\end{array}$ & $\begin{array}{l}160.00 \pm 7.3 \\
1 * \\
(56.04 \%)\end{array}$ \\
\hline \multirow[t]{3}{*}{$\begin{array}{l}\text { Water } \\
\text { fraction }\end{array}$} & 250 & $\begin{array}{l}341.00 \pm 22 \\
.09\end{array}$ & $\begin{array}{l}330.76 \pm 48 \\
48 \\
(3.23 \%)\end{array}$ & $\begin{array}{l}330.76 \pm 21 . \\
90 \\
(3.23 \%)\end{array}$ & $\begin{array}{l}311.00 \pm 23 . \\
24 \\
(8.7 \%)\end{array}$ & $\begin{array}{l}300.00 \pm 23 . \\
22 * \\
(12.02 \%)\end{array}$ & $\begin{array}{l}292.00 \pm 23 . \\
53 * \\
(14.37 \%)\end{array}$ & $\begin{array}{l}200.00 \pm 18 \\
47^{*} \\
(41.34 \%)\end{array}$ & $\begin{array}{l}170.89 \pm 20 \\
09 * \\
(50.4 \%)\end{array}$ \\
\hline & 500 & $\begin{array}{l}344.02 \pm 14 \\
.89\end{array}$ & $\begin{array}{l}300.80 \pm 64 \\
92^{*}\end{array}$ & $\begin{array}{l}300.00 \pm 27 \\
86^{*}\end{array}$ & $\begin{array}{l}300.98 \pm 28 \\
53^{*}\end{array}$ & $\begin{array}{l}200.00 \pm 28 \\
00^{*}\end{array}$ & $\begin{array}{l}165.98 \pm 27 \\
87^{*}\end{array}$ & $\begin{array}{l}154.98 \pm 23 \\
66^{*}\end{array}$ & $\begin{array}{l}150.00 \pm 25 \\
02^{*}\end{array}$ \\
\hline & & & $(12.56 \%)$ & $(12.79 \%)$ & $(12.51 \%)$ & $(41.86 \%)$ & $(51.75 \%)$ & $(54.95 \%)$ & $(56.39 \%)$ \\
\hline
\end{tabular}




\subsection{Effect on serum lipid profile}

The levels of triglyceride, total cholesterol and LDL-C were significantly $(p<0.05)$ elevated and the level of serum HDL-C was decreased in the diabetic control group as compared to normal control.
After supplementation with methanol extract and fractions the alteration in lipid metabolism was significantly $(p<0.05)$ affected as evidenced by decreased serum triglyceride (TG), total cholesterol (TC) and LDL-cholesterol levels and increased HDL cholesterol concentration (Table 5)

Table 5: Effect of various treatments on serum lipid profile

\begin{tabular}{llllll}
\hline Treatment & $\begin{array}{l}\text { Dose } \\
\text { (mg/kg) }\end{array}$ & $\begin{array}{l}\text { Total cholesterol } \\
\text { (mg/d) }\end{array}$ & $\begin{array}{l}\text { Triglyceride } \\
\text { (mg/dl) }\end{array}$ & $\begin{array}{l}\text { HDL- } \\
\text { Cholesterol } \\
\text { (mg/dl) }\end{array}$ & $\begin{array}{l}\text { LDL-Cholesterol } \\
\text { (mg/dl) }\end{array}$ \\
\hline Normal control & Tween 80 & $169.93 \pm 6.72$ & $81.96 \pm 2.87$ & $93.77 \pm 4.32$ & $59.77 \pm 10.31$ \\
Diabetic control & Tween 80 & $290.00 \pm 0.79$ & $185.19 \pm 8.88$ & $43.77 \pm 4.69^{*}$ & $108.55 \pm 6.65^{*}$ \\
Glibenclamide & 5 & $176.28 \pm 5.58$ & $127.58 \pm 5.03$ & $87.74 \pm 3.39$ & $63.02 \pm 2.12$ \\
Methanol Extract & 250 & $171.72 \pm 2.34^{*}$ & $88.38 \pm 3.59^{*}$ & $79.31 \pm 2.95^{*}$ & $74.74 \pm 2.27^{*}$ \\
& 500 & $170.91 \pm 1.71^{*}$ & $104.41 \pm 6.14^{*}$ & $87.85 \pm 3.93^{*}$ & $62.18 \pm 4.85^{*}$ \\
$\begin{array}{l}\text { Ethyl acetate } \\
\text { fraction }\end{array}$ & 250 & $150.35 \pm 10.37^{*}$ & $114.39 \pm 4.19^{*}$ & $82.16 \pm 3.60^{*}$ & $82.31 \pm 9.75^{*}$ \\
n-hexane & 500 & $164.07 \pm 3.44^{*}$ & $133.28 \pm 11.7^{*}$ & $66.60 \pm 2.28$ & $70.82 \pm 3.75^{*}$ \\
fraction & 250 & $175.63 \pm 5.33^{*}$ & $119.38 \pm 4.71^{*}$ & $85.22 \pm 2.63^{*}$ & $66.53 \pm 5.58^{*}$ \\
Butanol fraction & 250 & $173.35 \pm 0.96^{*}$ & $66.64 \pm 5.98^{*}$ & $84.57 \pm 1.81^{*}$ & $75.46 \pm 0.94^{*}$ \\
& 500 & $175.05 \pm 3.44^{*}$ & $83.75 \pm 3.03^{*}$ & $81.06 \pm 3.43^{*}$ & $95.24 \pm 4.38$ \\
Water fraction & 250 & $155.89 \pm 6.77^{*}$ & $116.89 \pm 8.43^{*}$ & $78.43 \pm 2.44^{*}$ & $77.08 \pm 7.73 \mathrm{v}$ \\
& 500 & $173.35 \pm 0.81^{*}$ & $101.92 \pm 3.79^{*}$ & $84.57 \pm 1.17^{*}$ & $68.40 \pm 2.18^{*}$ \\
\hline
\end{tabular}

$\mathrm{n}=5 . * \mathrm{p}<0.05$ when compared to diabetic control

\subsection{Effect on body weight}

There was reduction in the body weight of the animals after induction of diabetes with alloxan monohydrate. A significant $(\mathrm{p}<0.05)$ increase in body weight was noticed after treatment with the extract and fractions (Table 6).

Table 6: Effect of various treatments on body weight

\begin{tabular}{lllllc}
\hline Treatments & Dose $\mathbf{( m g / k g )}$ & $\begin{array}{l}\text { Weight before } \\
\text { alloxan }\end{array}$ & $\begin{array}{l}\text { Weight after } \\
\text { alloxan }\end{array}$ & $\begin{array}{l}\text { Weight after } \\
\text { treatment }\end{array}$ & $\begin{array}{l}\text { Change in } \\
\text { weight (\%) }\end{array}$ \\
\hline Normal control & Tween 80 & $25.18 \pm 1.33$ & $17.46 \pm 0.67$ & $27.60 \pm 1.21$ & 36.74 \\
Diabetic control & Tween 80 & $26.88 \pm 1.64$ & $18.00 \pm 1.05$ & $19.20 \pm 1.07^{*}$ & 6.25 \\
Glibenclamide & 5 & $23.72 \pm 3.05$ & $18.06 \pm 1.14$ & $20.20 \pm 2.59$ & 10.59 \\
Extract & 250 & $24.22 \pm 2.87$ & $17.94 \pm 0.73$ & $22.20 \pm 2.63$ & 19.19 \\
& 500 & $28.00 \pm 1.52$ & $17.60 \pm 0.75$ & $24.40 \pm 1.60^{*}$ & 27.87 \\
Ethyl acetate fraction & 250 & $30.80 \pm 1.24$ & $18.40 \pm 1.03$ & $27.00 \pm 1.82^{*}$ & 31.85 \\
& 500 & $24.40 \pm 2.23$ & $19.00 \pm 1.08$ & $22.20 \pm 2.46$ & 14.41 \\
n-hexane fraction & 250 & $23.60 \pm 1.69$ & $18.74 \pm 0.56$ & $23.60 \pm 1.72^{*}$ & 20.59 \\
Butanol fraction & 500 & $26.20 \pm 2.89$ & $19.00 \pm 1.58$ & $22.20 \pm 2.15$ & 14.41 \\
Water fraction & 250 & $25.80 \pm 1.77$ & $17.60 \pm 0.69$ & $21.80 \pm 1.39$ & 19.27 \\
& 500 & $27.80 \pm 2.40$ & $18.20 \pm 0.66$ & $22.60 \pm 2.84^{*}$ & 19.47
\end{tabular}

$\left.\mathrm{n}=5{ }^{*} \mathrm{p}<0.05\right)$ ) when compared to diabetic control 


\subsection{Histopathology}

The pancreas of the non diabetic normal control mice (Group 1) showed sheets of normal sized glands lined by columnar epithelium with basally located nuclei surrounded by vesicular cytoplasm. Interspersed within these glands are islands of normal sized Islet of Langerhans. There was normal pancreatic histoarchitecture of islet $\beta$ cells (Figures $1 \mathrm{~A} \& \mathrm{~B})$. The pancreas of the diabetic mice untreated (Group 2) were severely degenerated, and showed sheets of small sized glands lined by columnar epithelium with basally located nucleus and vesicular cytoplasm. No Islet of Langerhan was seen (Figures 1C \& D). Photomicrograph of a pancreatic section of Group 3, (glibenclamide treated diabetic mice) (Figures $1 \mathrm{E} \& \mathrm{~F}$ ) revealed normal histoarchitecture with increased number of islet cells when compared to the untreated Group 2 that were severely degenerated. Histological examinations revealed a mildly distorted architecture of the pancreatic $\beta$ cells islet of diabetic mice in group 4, 6, 8, 10 and 12 treated with low doses $(250 \mathrm{mg} / \mathrm{kg})$ of methanol extract and different fractions (Figures 2C \& D, 3C \& D, 4C \& D, 5C \& D and 6C \& D). Diabetic Groups 5 and 7 that were treated with high dose (500 mg/kg) of the crude extract and EF also had mildly despaired architecture of the pancreatic $\beta$ cells islet (Figures $2 \mathrm{E} \& \mathrm{~F}$, and $3 \mathrm{E} \& \mathrm{~F}$ ). Histological examinations showed a marked rejuvenation of the pancreatic $\beta$ cells islet of diabetic mice in Groups 9, 11 and 13 treated with high doses (500 $\mathrm{mg} / \mathrm{kg}$ ) of $\mathrm{HF}, \mathrm{BF}$ and $\mathrm{WF}$ (Figures $4 \mathrm{E} \& \mathrm{~F}, 5 \mathrm{E} \& \mathrm{~F}$ and $6 \mathrm{E}$ \& F) . The pancreas of all the diabetic mice (Groups 4 - 13), treated with the two doses of the methanol extract and fractions, showed clusters of variably sized regenerated Islet of Langerhans within sheets of normal exocrine pancreas.
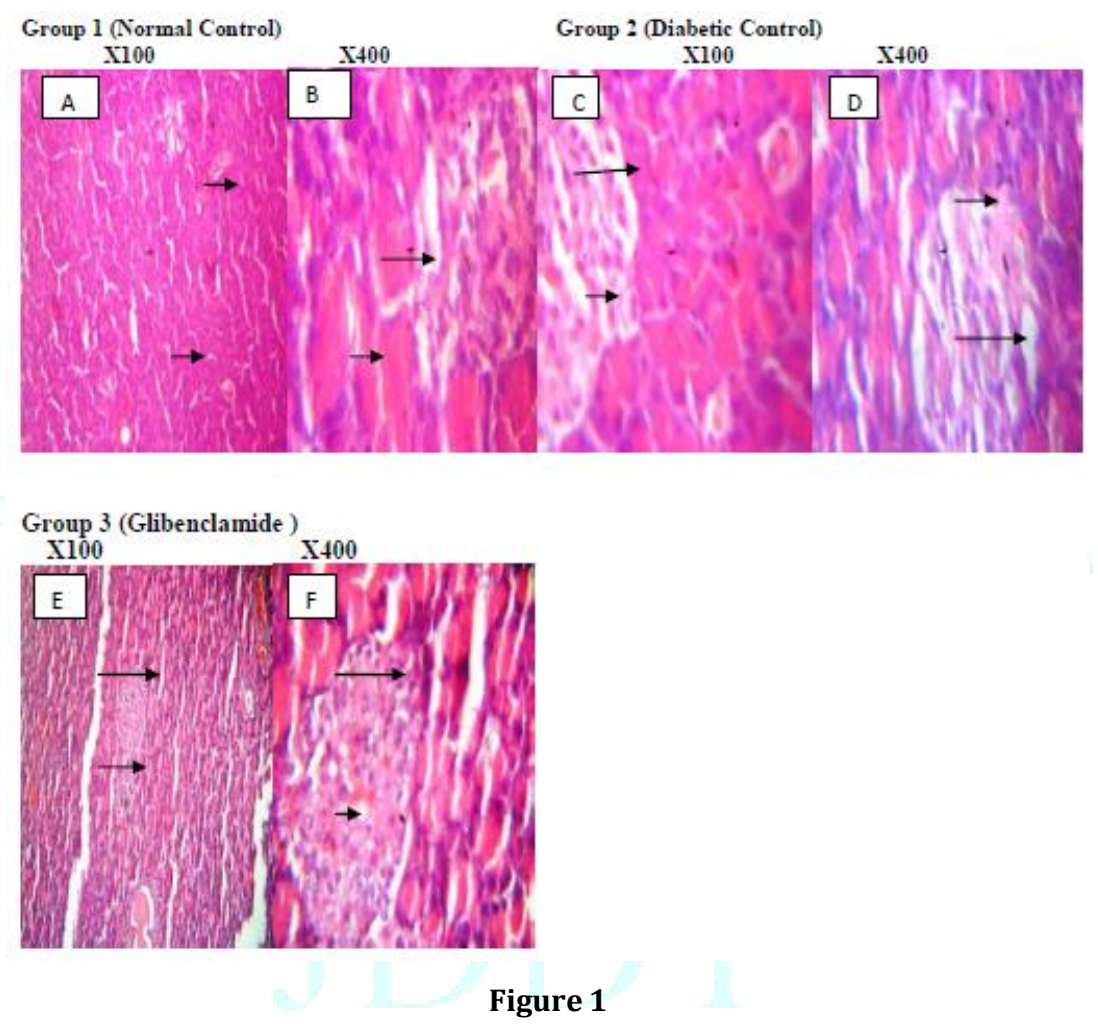

Group 1 (Plates A and B).Pancreas of normal control group revealed acinar pattern structure with pyknotic nuclei of some acinar cells appearing. The acinar cells which stained strongly are arranged in lobules with prominent nuclei. The islet cells are seen embedded within the acinar cells and surrounded by a fine capsule (arrow). Photomicrograph of the pancreas showed normal atrophic pancreatic islet

Group 1 (Plates A and B) compared with Group 2 (Plates C and D). Group 2 (diabetic) pancreas features showed some acinar cells with islet-cells showing congested pyknotic nuclei (short arrow) with visible Lymphocytic infiltrates (long arrow). Photomicrograph of the pancreas showed atrophic pancreatic islet with vacuolations which indicates significant damaged Islets of Langerhans in the beta cells.

Group 3 (Plates E and F) compared with Group 2 (Plates A and $B$ ). The pancreas of this group (Glibenclamide treated) revealed acinar pattern structure with pyknotic nuclei of some acinar cells (short arrow). The acinar cells which stained strongly are arranged in lobules with prominent nuclei. The islet cells are seen embedded within the acinar cells and surrounded by a fine capsule (long arrow). Photomicrograph shows the regenerative effect of Glibenclamide (Standard drug). 

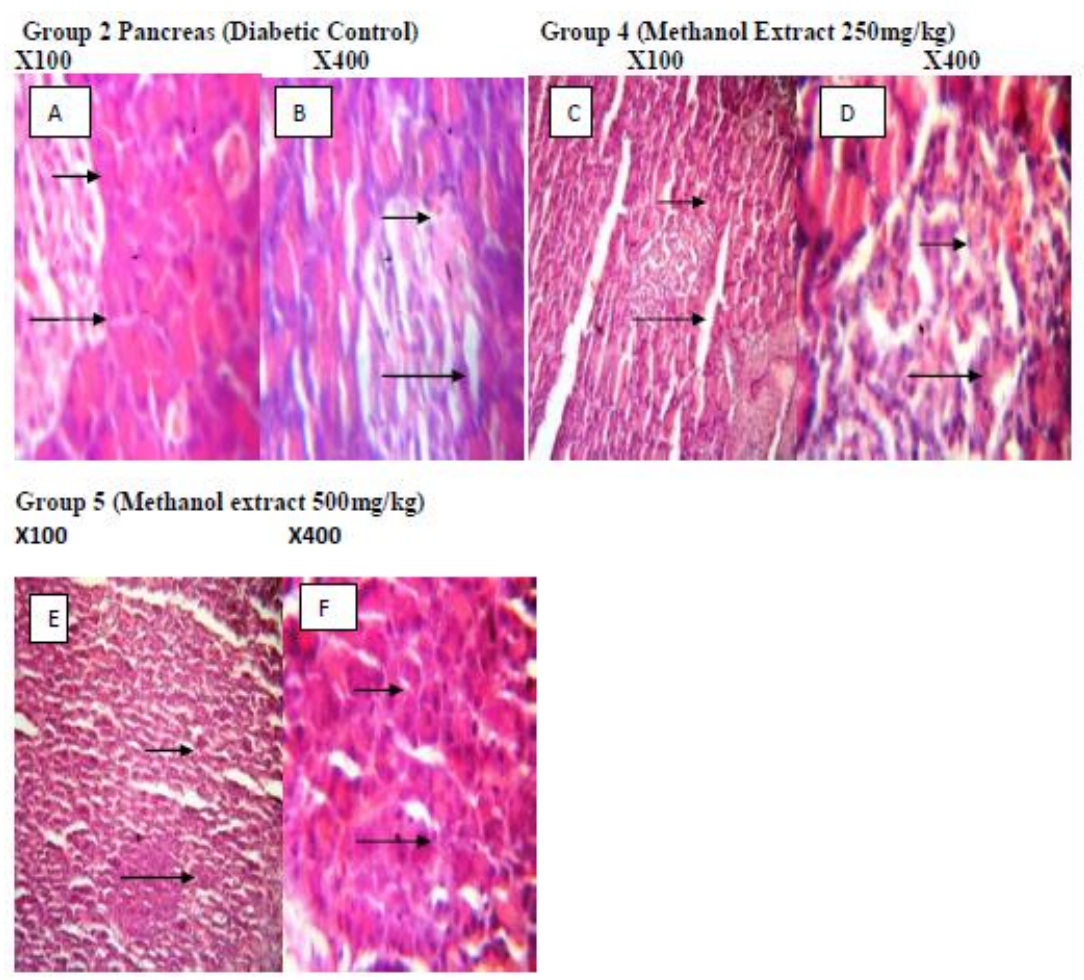

Figure 2

Group 4 (Plates C and D) compared with Group 2 (Plates A and B). The pancreas of this group (ME $250 \mathrm{mg} / \mathrm{kg}$ ) showed some acinar cells with islet-cells showing mildly despaired pyknotic nuclei (long arrow) with mild Lymphocytic infiltrates (short arrow). Photomicrograph reveals regenerative effect of the methanol extract $(250 \mathrm{mg} / \mathrm{kg})$
Group 5 (Plates E and F) compared with Group 2 (Plates A and B). The pancreas of this group (ME $500 \mathrm{mg} / \mathrm{kg}$ ) showed some acinar cells with islet-cells showing mildly despaired pyknotic nuclei (long arrow) with visible Lymphocytic infiltrates (short arrow).The photomicrograph shows the regenerative effect of methanol extract $(500 \mathrm{mg} / \mathrm{kg})$.
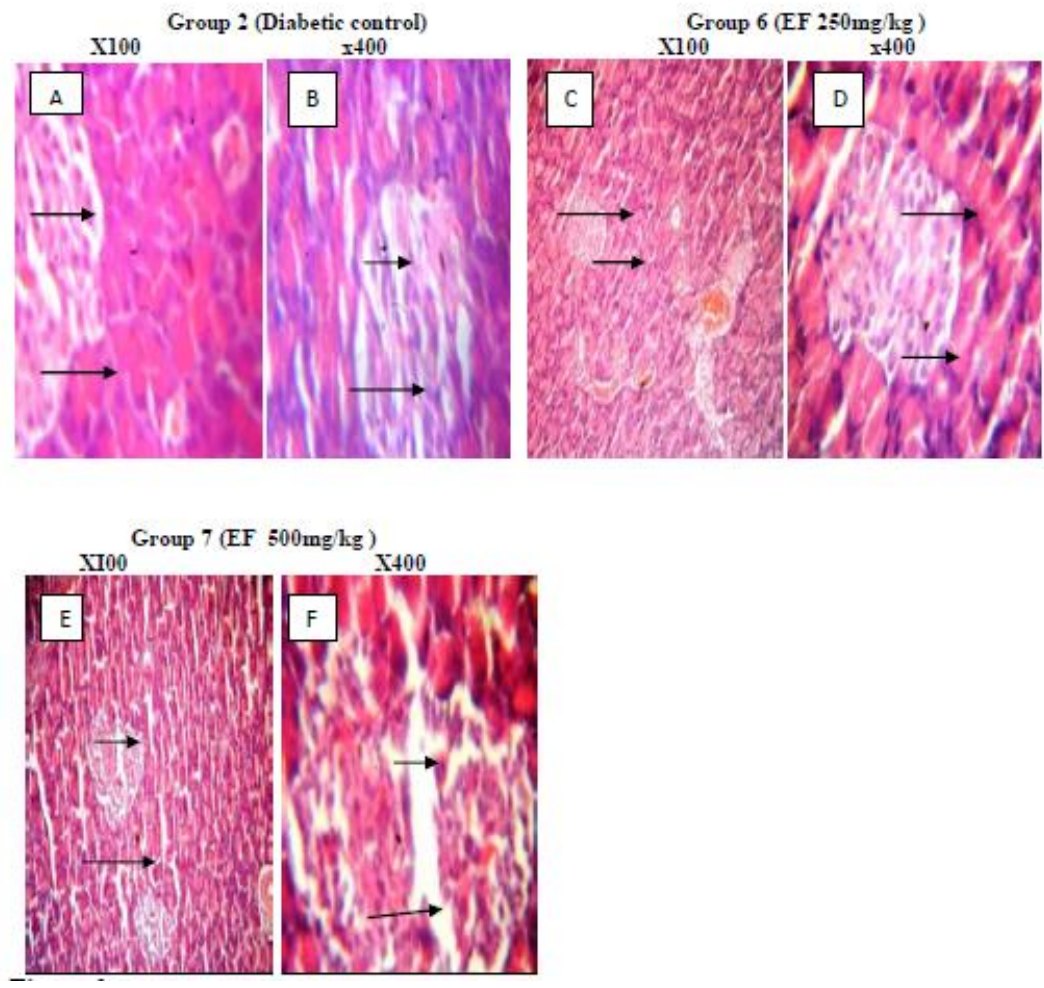

Figure 3

Group 6 (Plates C and D) compared with Group 2 (Plates A and B). The pancreas of this group (EF $250 \mathrm{mg} / \mathrm{kg}$ ) revealed secretory acini with bulky pancreatic islet (long arrow). The histology reveals intralobular duct at low power (short head). Photomicrograph showed regenerative effect of the ethyl acetate fraction $(250 \mathrm{mg} / \mathrm{kg})$
Group 7 (Plates E and F) compared with Group 2 (Plates A and B). The pancreas of this group (EF $500 \mathrm{mg} / \mathrm{kg}$ ) showed some acinar cells with islet-cells showing mildly despaired pyknotic nuclei (long arrow) with mild Lymphocytic infiltrates (short arrow). The Photomicrograph shows the regenerative effect of ethyl acetate fraction $(500 \mathrm{mg} / \mathrm{kg})$. 

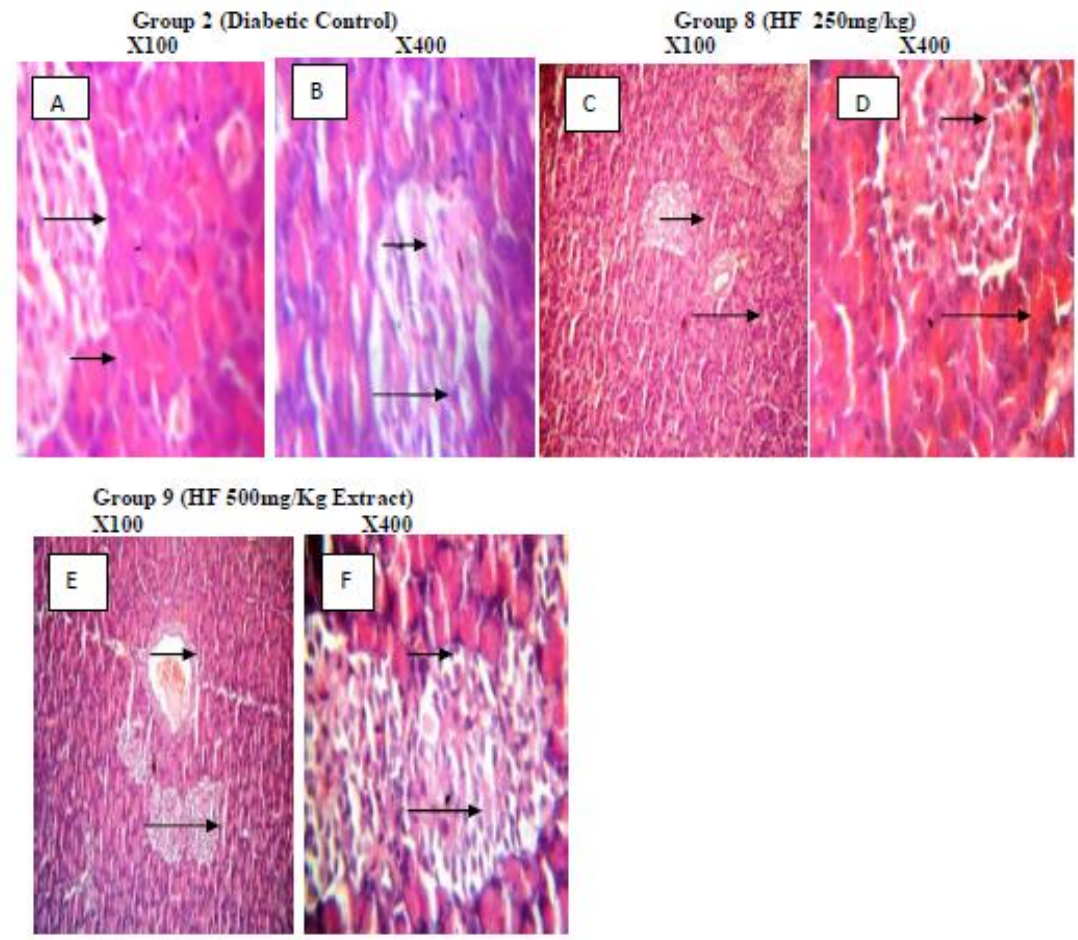

Figure 4

Group 8 (Plates C and D) compared with Group 2 (Plates A and B). The pancreas of this group (HF $250 \mathrm{mg} / \mathrm{kg}$ ) reavealed secreterory acini with bulky pancreatic islet (long arrow). The histology revealed intralobular duct at low power (short arrow). The Photomicrograph shows the regenerative effect of $\mathrm{n}$-hexane $\mathrm{l}$ fraction $(250 \mathrm{mg} / \mathrm{kg})$
Group 9 (Plates E and F) compared with Group 2 (Plates A and B). The acinar cells of this group (HF $500 \mathrm{mg} / \mathrm{kg}$ ) which stained strongly are arranged in lobules with prominent nuclei. The islet cells are seen embedded within the acinar cells and surrounded by a fine capsule (long arrow).The Photomicrograph shows the regenerative effect of n-hexane fraction (500 mg/kg).
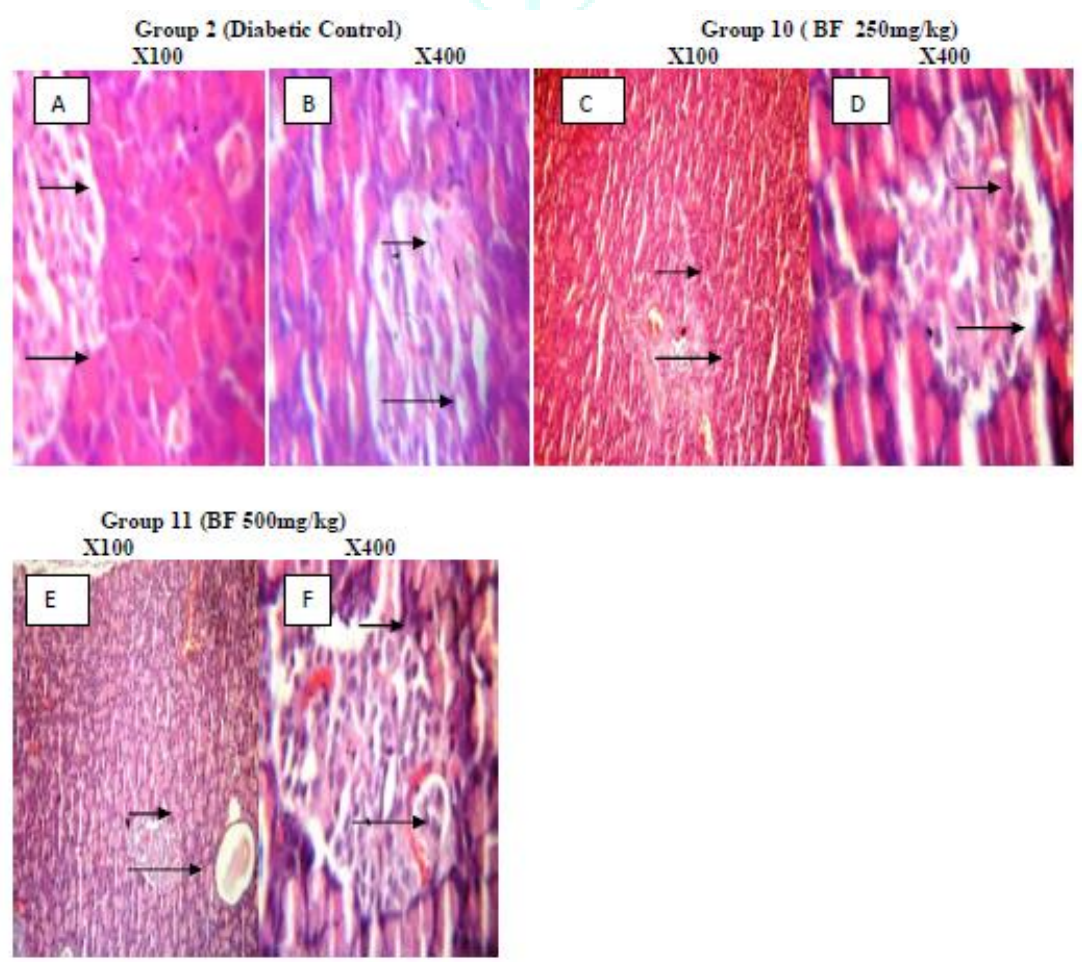

Figure 5

Group 10 (Plates C and D) compared with Group 2 (Plates A and B). The pancreas of this group (BF $250 \mathrm{mg} / \mathrm{kg}$ ) revealed secreterory acini with bulky pancreatic islet (long arrow). The histology reveals intralobular duct at low power (short arrow). The photomicrograph shows the regenerative effect of butanol fraction $(250 \mathrm{mg} / \mathrm{kg})$

Group 11 (Plates E and F) compared with Group 2 (Plates A and B). The pancreas of this group (BF $500 \mathrm{mg} / \mathrm{kg}$ ) revealed acinar pattern structure with pyknotic nuclei of some acinar 
cells appearing (short arrow). The acinar cells which stained strongly are arranged in lobules with prominent nuclei. The islet cells are seen embedded within the acinar cells and surrounded by a fine capsule (long arrow). The photomicrograph shows the regenerative effect of butanol fraction $(500 \mathrm{mg} / \mathrm{kg})$.
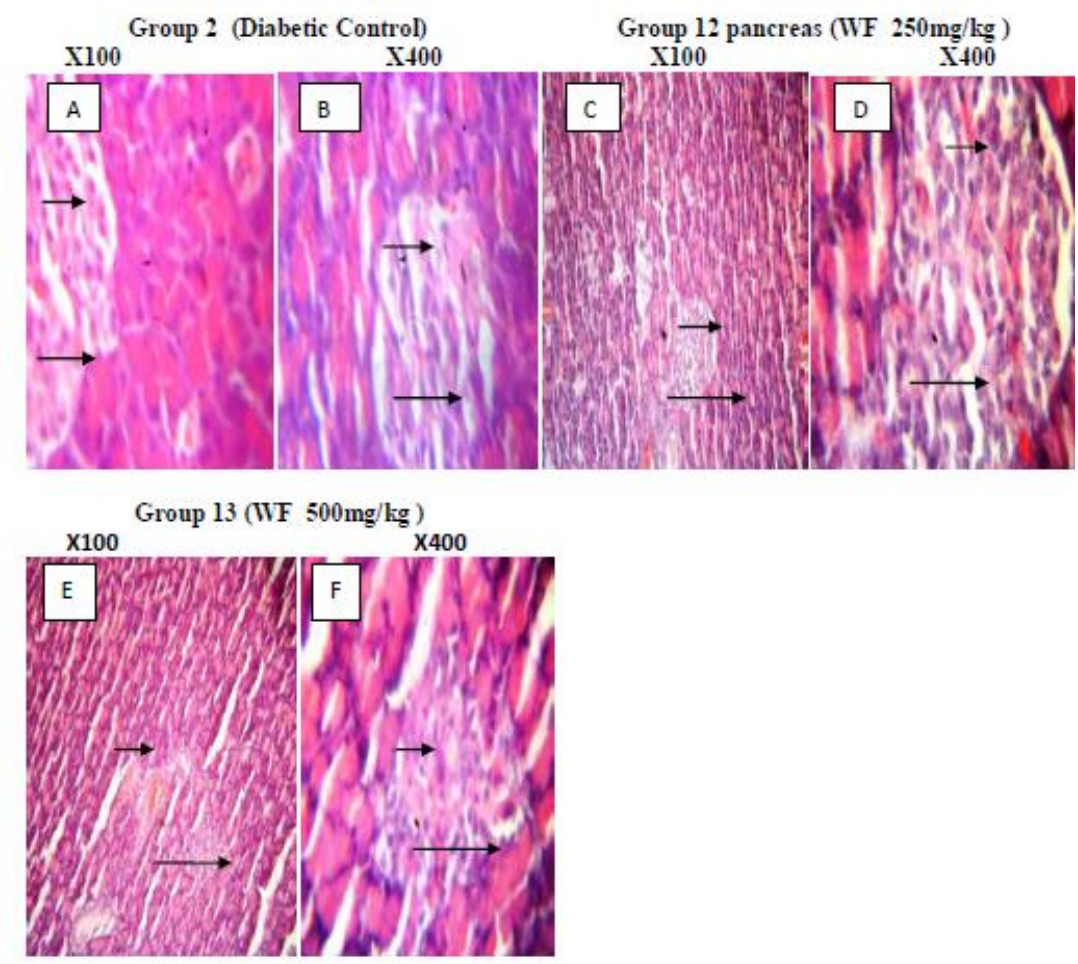

Figure 6

Group 12 (Plates C and D) compared with Group 2 (Plates A diabetic mice by elevated triglycerides, total cholesterol, LDLand B). The pancreas of this group (WF $250 \mathrm{mg} / \mathrm{kg}$ ) revealed $\mathrm{C}$ and decreased HDL-C, and these constitute important secretory acini with bulky pancreatic islet (long arrow). The histology reveals intralobular duct at low power (short arrow). The photomicrograph indicates the regenerative effect of water fraction $(250 \mathrm{mg} / \mathrm{kg})$

Group 13 (Plates E and F) compared with Group 2 (Plates A and B). The pancreas of this group (WF $500 \mathrm{mg} / \mathrm{kg}$ ) revealed secretory acini with bulky pancreatic islet (long arrow). The nucleus appears pyknotic. The photomicrograph indicates the regenerative effect of water fraction $(500 \mathrm{mg} / \mathrm{kg})$

\section{DISCUSSION}

In this study, the crude methanol extract and fractions of $D$. tripetala reduced fasting blood glucose levels in alloxan induced diabetic mice when compared to the untreated diabetic control. The glucose lowering effect of the extract and fractions may be due to the stimulation of $\beta$ - cells of pancreatic islets [27] akin to the action of glibenclamide, a sulphonylurea known to produce hypoglycemic effect primarily through release of insulin from the pancreatic $\beta$ cells [28]. The results of these studies are in line with previous report on some plants with similar phytoconstituents, which have been confirmed to have both, in-vivo and in-vitro antidiabetic activity $[29,30,31]$.

The presence of flavonoids and saponins has previously been reported in ethanolic fruit extracts of L. camara which demonstrated hypoglycemic activity in streptozotocin induced diabetic male Wistar rats [32]. Flavonoids act on various molecular targets and regulate different signaling pathways in pancreatic $\beta$-cells, hepatocytes, adipocytes and skeletal myofibers [33]. Saponin fraction isolated from Momordica charantia reduced blood glucose levels and increased insulin secretion and glycogen synthesis in alloxan induced diabetic mice [34]. Diabetic dyslipidaemia is marked in alloxan induced cardiovascular risk factors [29]. The extract and fractions supplementation resulted in significant attenuation in the level of serum HDL-C. After supplementation with the extract and fractions, the alteration in lipid metabolism was significantly attenuated as evidenced by decreased serum triglyceride (TG), total cholesterol (TC), and LDL-cholesterol levels and increased HDL-cholesterol concentration in diabetic mice. These findings are in agreement with that of Kaleem et al. [35], who reported that the ethanolic extract of Nigella sativa seeds produced significant decrease in serum lipid profile. The reduction in serum total cholesterol concentration by the extract is beneficial and may reduce the risk of cardiovascular disease. Elevated HDL-C is very significant in human health because it improves the transportation of cholesterol from plasma to the liver for biotransformation and excretion, thereby preventing atheroma formation and blood vessel occlusion (Nwajo, 2015).

Aja et al. [37], reported a significant $(\mathrm{P}<0.05)$ decrease in the body weight of alloxan diabetic rats and a significant increase following the administration of ethanol extract of Cajanus cajan leaf. This is consistent with the observation of the World Health Organization, that diabetes mellitus is often characterized by rapid and significant weight loss leading to fatigue which is not easily reversed. Photomicrograph of the pancreas showed atrophic pancreatic islet with vacuolations which indicates significant damaged Islets of Langerhans in the beta cells. The regenerative effect of the extract and fractions on the pancreatic cells indicate possible secretagoge effects on the production of insulin. The regeneration of the Islets of Langerhans may be due to the effect of the extract and fractions on the pancreatic cells, which resulted in the production of insulin. 
The results of this study show that the methanol leaf extract and fractions of Dennettia tripetala can be used to manage diabetes. This confirms the local use of the plant in the treatment of diabetes by the indigenous people of Nigeria.

\section{Compliance with ethical standards}

\section{Conflict of interest}

The authors declare that they don't have any conflict of interest.

\section{Research involving human participants and/or animals}

Animals (albino mice) were purchased from the Laboratory Animal Facility of the Department of Veterinary Physiology and Pharmacology, University of Nigeria, Nsukka and transferred to the animal House of the Department of Pharmacology and Toxicology, Nnamdi Azikiwe University. They were housed in clean metal cages, with free access to water and feed (Guniea Feed $\AA$, Nigeria). Animals were handled in compliance with the National Institute of Health Guidelines for care and use of laboratory animals (Pub No. 8523, revised 1985).

\section{Authors Contributions}

MAO performed the experiments under the supervision of PAA while CUA prepared the manuscript

\section{REFERENCES}

1. Kristova, V., Liskoya, S., Sotnikova, S., Vojtko, R. and Kurtansky, A Sulodexide improves endothelial dysfunction in streptozotocininduced diabetes in rats. Physiolo Res 2008; 5: 491-494.

2. American Diabetes Association. Diagnosis and classification of diabetes mellitus. Diabetes Care. 2005: 28: 37-42.

3. Scoppola, A., Montecchi., F. R., Mezinger, G., and Lala, A. Urinary mevalonate excretion rate in type 2 diabetes: Role of metabolic control. Atherosclerosis. 2001; 156: 357-361.

4. Owu, D. U., Antai, A. B., Udofia, K. H., Obembe, A. O., Obasi, K. O. and Eteng, M. U. Vitamin C improves basal metabolic rate and lipid profile in alloxan-induced diabetes mellitus in rats. J Biosci, 2006 31(5); 575-579.

5. Kesavulu, M. M., Giri, R., Kameswara., R. B. and Apparao., C. Lipid peroxidation and antioxidant enzyme levels in type 2 diabetic with microvascular complications. Diabetic Metab 2000; 26: 387 392.

6. Nayeemunnisa, A. Alloxan diabetes-induced oxidative stress and impairment of oxidative defense system in rat brain: neuroprotective effects of Cichorium intybus. Inter J Diabetes Metab. 2009; 17: 105-109.

7. Trivedi, N. A., Majumder, B., Bhatt, J. D., and Hemavathi, K. G. Effect of Shilajit on blood glucose and lipid profile in alloxan- induced diabetic rats. Indian J Pharmacol. 2004; 36: 373-76.

8. Venkatesh, S., Reddy, G. D., Reddy, B. M. and Ramesh. Antihyperglycemic activity of Carulluma attenuate. Fitoterapia. 2003; 74: 274-277.

9. Bailey, C. J. and Day, C., 1989. Traditional plant medicines as treatments for diabetes. Diabetes Care. 1989; 12: 553-564.

10. Grover, J. K., Yadav, S., and Vats, V. Medicinal Plants of India with Antidiabetic Potential. J Ethnopharmacol, 2002; 81: 81-100.

11. Hutchinson, J. and Dalziel, J. M. Flora of West Africa. Crown Agents for Oversea Government and Administrative mill bank, London, 1954. pp 50-51

12. Okiy, G. E. Indigenous Nigerian food plants. J West Afr Sci Asso 1960; 6: 117-121.

13. Oyemitan, I. A. Evaluation of Dennettia tripetala G. Baker (Annonaleae) for central nervous system activities. Ile-Ife, Nigeria: Department of pharmacology, Obafemi Awolowo University; An M. Phil thesis. 2006.

14. Achinewhu, S. G., Ogbonna, C. and Hard, A. D. Chemical composition of indigenous wild herbs, spices fruits and leafy vegetables used as food. Plant Food and Hum Nutr. 1995; 48: 341388.

15. Lewis, K. and Ausubel F. M. Prospect for plant-derived antibacterials. Nat Biotechnol. 2006; 24(12): 1505-1507
16. Nwaogu, L. A., Alisi, C. S. and Ibegulem, C. O. Evaluation of $\beta-$ carotene content and presence of some Phytochemical in Five indigenous Fruits. Plant Prod Res J. 2015; 10: 13-14.

17. Kumar, P. P., Kumaravel, S. and Lalitha, C. Screening of antioxidant activity, total phenol and GC-MS study of Vitex negundo. Afr J Biochem Res. 2010; 4(7): 191-195

18. Oyemitan, I. A., Iwalewa, E.O., Akanmu, M. A., and Olugbade, T. A Antinociceptive and anti-inflammatory effects of essential oil of Dennettia tripetala G. Baker (Annonaceae) in rodents. Afr J Trad Compl Alter Med. 2017; 5: 355-362.

19. Ihekwereme, C. P., Chukwuson, M. A., Erhirhie, E. O. and Uche, G. O. (2016). Preliminary evaluation of the anti-emetic activity of crude methanol extract and fraction of Ocimum gratissimum. J Dev Drugs. 2016; 5 (1): 2329-6631

20. Salim, M. A., Imam, A. A., Dikko, A. A. U., Tanko, Y. and Mohammed, A. Effect of Aqueous Garlic (Ag) Extract of vitex sumplicifolia on blood glucose level, liver glycogen content, lipid profile and antioxidant vitamins in alloxan induced diabetic wistar rats. Bayero J Biomed Sci. 2016; 1(1): 179-157.

21. Ezeigbo, I. Antidiabetic potential of methanolic leaf extracts of Icacina trichantha in alloxan-induced diabetic mice. Inter J Diabetes Dev Countr. 2010; 30(3): 150-152.

22. Tietz, N. W. Clinical guide to Laboratory tests, Second edition W.B. Saunders Company, Philadelphia, USA, 2014; pp 554-556.

23. National Institute of Health Consensus Development Conference Statement (NIHCDCS). Triglyceride, High Density Lipoprotein and Coronary Heart Disease. Washington D.C. 1992

24. Friedewald, W. T., Levy, R. I. and Fredrickson, D. S. Estimation of the concentration of low-density lipoprotein cholesterol in plasma, without use of the preparative centrifuge. Clin Chem. 2017; 18:499-500.

25. Slaoui, M. and Fiette L. Histopathology procedures: From tissue sampling to histopathological evaluation. Methods Mol Biol. 2014; 691: 69-82.

26. Godwin, A. (2015). Histochemical uses of haematoxylin - A Review. J Phys Chem Solids. 2015; 1:24-34.

27. Krishnakumar, K., Augusti, K. T. and Vijayammal, P. L. Hypoglycemic and anti-oxidant activity of Salacia oblonga wall extract in streptozotozin induced diabetic rats. Indian J Physiol Pharmacol. 2015; 43(3): 510 - 514.

28. Agila K. N. and Kavitha, R. Antidiabetic, antihyperlipidaemic and antioxidant activity of Oxalis corniculata in alloxan induced diabetic mice. Journal of Natural Sciences Research. 2012; 2(7): 917.

29. Akah, P. A., Okoli C .O., Ibiam, A. F., Ezike A. C. and Okoye T. C. Evaluation of antidiabeticpotentials of Phyllanthus niruri in alloxan diabetic rats. Afr J Biotechnol.2010; 9: 248-259.

30. Mbaka, G. O., Ogbonnia, S. O., Oyeniran, K. J. and Awopetu, P. I. Effect of Raphiahookeri seed extract on blood glucose, glycosylated haemoglobin and lipid profile of alloxan induced diabetic rats. Bri J Med Medic Res. 2015; 2(4): 621-635.

31. Arika, W. M., Abdirahman, Y. A., Mawia, M. A., Wambua, K. F., Nyamai, D. M., Ogola, P. E., Kiboi, N. G., Nyandoro, H. O., Agyirifo, D. S., Ngugi M. P. and Njagi, E. N. M. In Vivo antidiabetic activity of the aqueous leaf extract of Croton macrostachyus in alloxan induced diabetic mice. Pharmaceut Analyt Acta. 2015 ;2153-2435.

32. Piero, N. M., Kimuni, N. S., Ngeranwa, J. J. N., Orinda., G. O. and Njagi, J. M. Antidiabetic and Safety of Lantana rhodesiensis in Alloxan Induced Diabetic Rats. J Clin Biochem Nutr. 2015; 40: 163173.

33. Babu, P. V., Liu, D. and Gilbert, E. R. Recent advances in understanding the anti-diabetic actions of dietary flavonoids. $J$ Nutrl Biochem. 2013; 24: 1777-1789.

34. Zheng, T., Shu, G., Yang Z, Mo, S., and Zhao, S. Y. Antidiabetic effect of total saponins from Entada phaseoloides (L.) Merr. in type 2 diabetic rats. J Ethnopharmacol. 2012; 13.

35. Kaleem, M., Kirmani, D., Asif M., Ahmed, Q. and Bano, B. (2015) Biochemical effect of Nigella sativa L. seeds in diabetic rats. Indian J Expt Bio. 2015; 44:745-748.

36. Nwajo, H. U. Efficacy of aqueous leaf extract of Vernonia amygdalina on plasma lipoproteins and oxidative status in diabetic rat model. Nig J Physiol Sci. 2015; 20: 39-42.

37. Aja, P. M., Ibekwe, V. I., Ekpono, E. U., Ugwu, P. C. and Okechukwu, P. C. Effect of ethanol extract of Cajanus cajan leaf on plasma lipid level in albino rats. Inter J Cur Res Acad Rev. 2015; 3(1): 161-167. 